\title{
1 Introduction: Aim, Concept and Biases
}

The archaeology of Greek and indigenous southern Italy of the first millennium BC is usually seen as a part of the domain of Classical Archaeology. This means that it was mostly studied by archaeologists who were educated in classics-oriented departments. Here a traditional culture-historical approach often dominated in which the ancient written sources played a major role. This is also the educational background of the author of this book. In 1970 the archaeology of the Mediterranean in the Netherlands was basically a specific form of cultural history. Since that time the domain has changed enormously with the rise of the survey and landscape archaeology, the immensely increasing importance of the data from the sciences and the introduction of anthropological concepts and ideas. The culture-historical paradigm, moreover, has lost its dominant position. We have seen the rise of the New Archaeology followed by the wide variety of approaches that characterizes the post-modern archaeology. Though these more recent paradigms have their flaws and advantages, they all contributed in a significant way to more nuanced approaches resulting in a better insight into the past.

This book deals with a millennium that witnessed a series of unprecedented changes. In these centuries many Mediterranean societies changed from a great variety of small, predominantly tribal entities into the enormous state currently indicated as the Roman Empire. The main aim of this book is to offer a new and coherent narrative of change of a particular region (southeast Italy) during a specific period of its history (1st millennium BC). In this book I wish to produce an overview consisting of dynamic images of the societies that lived in that region in a distant past. During the construction of these images questions are asked and explanations are offered. The latter sometimes differ from the traditional views on such matters and I seem to have shocked some of my Italian colleagues. ${ }^{1}$ The narrative presented here has been foreshadowed in papers in which I questioned the current views on the early Roman period ('Hannibal's legacy'), on the sudden rise of the Lucanians and the Greek 'colonization' of southeast Italy. ${ }^{2}$

In this narrative the landscapes and the human impact on landscapes will receive particular attention. A comparative study in settlement and land-use dynamics ('Regional Pathways to Complexity') regarding two regions of southern Italy and Latium was published in 2010 by Attema, Burgers and Van Leusen, with whom I have cooperated intensely. The changing character of the manmade landscapes (both urban and rural) will be a recurring item in each of the chapters of this volume as well. Most chapters close with a summary containing a personal view on what I believe are the most important aspects of a particular period in the history of southeast Italy.

After two short introductory chapters containing background information (Chapter 2: 'The Bronze Age'; Chapter 3: 'The Land and the People') the narrative starts with the Iron Age. Though the Iron Age societies were doubtlessly rooted in the Bronze Age, the people who lived in Iron Age southeast Italy created entirely new societies with characteristics that differed vastly from those of the Late Bronze Age. The four chapters dealing with subsequent periods (chapters 4-7) make up the core of this book. In these I follow mainly the most current subdivision in Italian archaeology which separates the Iron Age (9th-7th centuries BC) from the Archaic-Classical period (6th-late 4th century BC) and the

Cf. Greco 2005 and 2011.

2 For the early Roman period, see Yntema 1995, 2006 and 2009; for the rise of the Lucanians, see Yntema
1997; for new light on Greek colonization ('a stone in the pond' according to some Italian colleagues), see Yntema 2000 and 2011. 
(early)-Hellenistic period (late 4th- 3rd century BC). Usually narratives on southern Italy stop with the Roman conquest of the region (272-265 BC). It should, however, be noted that it was not the event itself, but especially its long term consequences that were important. In the first 70 years after the Roman victories the societies of southeast Italy evolved in a very gradual way, but they changed in a truly dramatic way in the 2 nd century BC. Therefore, I have added a chapter discussing southeast Italy under Roman dominance (late 3rd- early 1st century BC).

The narrative necessarily stops at the beginnings of the 1st century BC. The reason for this is that both the archaeological evidence and the information supplied by ancient authors becomes very scarce indeed from this time onward. For the 1st century BC and the 1st century AD the meager evidence comes from only a few spots and does not suffice to produce images of southeast Italy that go beyond the present stereotypes. ${ }^{3}$ This means that the probably most intense phase of Roman influence on the district is sadly missing. There is still insufficient evidence to study, for instance, the important process of municipalization (1st century BC) and to trace the effects of the lex Plautia Papiria (89 BC) that made all free born south-Italians with both Greek and indigenous roots into citizens of the Roman state. The meager evidence concerning this period supplied by the ancient written sources has been collected by Kathryn Lomas. ${ }^{4}$

As we have seen above, the main aim of this book is to produce a decent overview of southeast Italy during the first millennium BC. An attempt to synthesize the present evidence seemed a useful undertaking, since the area under discussion has been subject to very numerous excavations and field surveys over the past thirty years. These were partly caused by development programs of the Council of Europe. European funds resulted in large infrastructural works and large-scale innovations in agriculture. These activities have caused very substantial damage to southeast Italy's archaeological heritage and resulted in an avalanche of rescue operations.

The data generated by these numerous and relatively recent activities have rarely been used to produce a general insight into the archaeology and history of the people that lived in southeast Italy during the first millennium BC. Of course, syntheses have been made in recent years. These, however, are invariably written in Italian and concern usually only limited parts of the region discussed here. They sometimes deal with present-day administrative entities such as the Italian regione of Basilicata or the regione Puglia, whilst an analysis of an area delineated by natural boundaries seems more adequate. The Greek groups and indigenous 'Italic' groups of southeast Italy have almost invariably been discussed separately, although their paths were strongly interwoven. ${ }^{5}$ Moreover, these syntheses are often characterized by a mainly cultural-historic approach. They have mostly been constructed in attempts to reconcile the artefactual data with the often patchy evidence from the ancient written sources. Important subjects such as urban and rural landscapes, social and societal change and interactions between the various groups and districts of the region have not been generously served. The important role of the ancient written sources in the construction of the past resulted, moreover, in 'indigenous' archaeologies seen through Greek and Roman eyes.

Research concerning the indigenous populations of southeast Italy has always been carried out in relation to the Greeks and the Romans: these 'peoples without history' have rarely been studied for their own sake. Greeks were implicitly seen as the centre, the natives were the periphery. The nonGreek tribes, for instance, were often said to have lived in the 'hinterlands' of Greek polities, whilst a good case can be made for viewing the south-Italian Greeks as a relatively marginal phenomenon in

3 For the full Roman period in southeast Italy, see, e.g. Lippolis 1997 and 2005 on Tarentum; Mertens 1995 on north-Apulian Herdoniae.
Lomas 1993

Greeks and non-Greeks have been discussed together in Bottini / Guzzo 1988. 
relation to the large native tribes that dominated well over $90 \%$ of the region under discussion. This Graeco-centric view has caused a considerable bias in research concerning the indigenous populations. The concept of this synthetic study is to deal with both Greek and indigenous groups together by attempting to shed the traditional biases of Graeco-centrism, Greek superiority and Greek-indigenous dichotomy. As for the early Roman period (chapter 7), the inhabitants of southeast Italy are not seen as poor and unresisting victims of Roman imperialism. They are presented as groups who devised strategies and took opportunities in order to solve problems caused by the rapidly changing world around them.

As early as 1974 the first overview of the pre-Roman archaeology of the Italian Basilicata region was composed. It was made by the late Dinu Adamesteanu. ${ }^{6}$ Most syntheses, however, were made during the 1980s. Overviews on pre-Roman Basilicata were made by Bruno D’Agostino, Angela Greco Pontrandolfo and Angelo Bottini. ${ }^{7}$ A compilation regarding the native cultures of Apulia was produced by Ettore De Juliis, whilst the pre-Roman phases in the north-Apulian district were highlighted in a excellent synthesis by the late Marina Mazzei and her collaborators. ${ }^{8}$ Continuity and change in the south-Apulian peninsula were mapped by Francesco D'Andria, ${ }^{9}$ whilst other aspects of the same district were discussed by various authors in the congress papers collected in I Messapi (30th Convegno di Studi sulla Magna Grecia, Taranto 1990). A good synthetic study of the Greek world of southern Italy (basically a handbook for university students) was composed by Emanuele Greco. ${ }^{10}$

The archaeology of pre-Roman southeast Italy has its own set of problems and biases. Foremost among these are the problems of chronology. These regard especially the 5th and the 3 rd centuries BC. The problem of the 5th century BC seemed to be that the period was largely absent. This missing 5 th century has conveniently been explained away (e.g. by the arrival of the Lucanians), but appears to have been caused predominantly by pottery typo-chronologies constructed on the basis of false assumptions. The problem will be discussed in some detail in chapter 6.1. The 3rd century BC was often problematical because of the widespread, implicit belief that the Roman conquest of southeast Italy (272-265) resulted in an almost complete void. Practically no one bothered to look into the period that followed these doubtlessly traumatic events, because it was believed to be a time of severe decline. However, the seriation of the tombs of the Greek polis of Taras and the analysis of the settlement contexts of the native-Italic site of Valesio have both produced ceramic typo-chronologies that tie in well and are probably reliable. ${ }^{11}$ They demonstrate that the 3 rd century BC was a period of substantial flourishing in both Taras and Valesio. Since the same 3rd-century BC pottery shapes have turned up in large numbers at almost every pre-Roman site of southeast Italy, the period is now quite well attested. Publications that appeared before the turn of the millennium, however, may still suffer from this bias.

The intensity of archaeological research in the various districts of southeast Italy varies considerably. The results of field activities are often presented in preliminary reports. Intensive field surveys have been carried out in various parts of Basilicata, in north- and south-Apulia, but are still absent in the central part of the latter region. Excavations have been carried out in considerable numbers in most

\footnotetext{
Adamesteanu 1974

D’Agostino 1974 and 1989, Greco Pontrandolfo 1982, and Bottini 1987.

8 For synthesis om pre-Roman Apulia, see De Juliis 1988; for north-Apulia (Daunia) see. Mazzei et al. 1984 and the posthumously published I Dauni-Archeologia
}

dal XI al V secolo a.C., Foggia 2010, by the same author.

$9 \quad$ E.g. D’Andria 1988.

10 Greco 1992.

11 For the seriation of the Taranto burials, see Lippolis 1994 and Graepler 1997; for the ceramics from the settlement contexts of Valesio, see Yntema 2001. 
districts. The main lacuna here is the district on the Adriatic Sea near Bari for which the archaeological evidence concerning the 1 st millennium $\mathrm{BC}$ is relatively meagre. ${ }^{12}$

As for the objects of the excavations: tombs and tomb groups have been dug up in many places. Till within the 1980s the archaeology of southeast Italy was predominantly an archaeology of tombs and funerary wares. Since these are in constant danger of being robbed by the infamous guilds of the clandestini, they have had a distinct priority in the superintendencies of both the regione Puglia and the regione Basilicata. Reports on large and fairly coherent burial plots, however, are rare, since most tombs were (and still are) found in rescue operations: often the majority of the graves of a burial group has been plundered..$^{13}$ Sanctuary sites which may contain vast quantities of votive offerings run the same risk. Mostly the layouts of the sacred places have been published, but usually little information is given on the quality, the quantity and the character of the votive offerings. ${ }^{14}$ There is still much to learn about the sacred places of southeast Italy. The excavations in the settlements that were often inhabited for hundreds of years and, therefore, have complicated stratigraphies, are time- and energy-consuming. They were rare till within the 1970s, but grew into a flood in the 1980s. Preliminary reports on these activities are fairly abundant, but final reports with detailed site plans, a representative selection of finds, interpretations and narratives on local developments are often lacking. For the two Greek poleis of Taras and Metapontion the scattered evidence has been compiled, whilst fairly detailed excavation reports are available for the settlement excavations at the Greek polis of Siris-Herakleia. ${ }^{15}$ There are very good reports on a rural site in the territory of Metapontion. ${ }^{16}$ Substantial reports have been published concerning tribal settlements of indigenous-Italic populations. These concern various sites in both Basilicata-Lucania and Apulia. ${ }^{17}$

12 Complete reports have been published on the field survey in the Bussento district in south-Campania (Gualtieri / Fracchia 2001), the field survey around south-Apulian Oria (Yntema 1993a) and five urban surveys in the same district (Yntema 1993b; Burgers 1998); there are excellent reports on the field surveys in the Metaponto area (e.g. Carter 2001, 2006; Carter / Prieto 2011) and on field surveys in western Apulia and the uplands of Basilicata by British-Canadian teams (e.g. Small 1991and 2001; and further literature cited there); for preliminary reports on north-Apulia, see Goffredo 2010 and Goffredo / Ficco 2010; for overview on central-Apulia, see Greiner 2003.

13 The most complete burial sites published hitherto are the $5^{\text {th }}-4^{\text {th }}$ century necropolises of Lavello in northeast Basilicata (Giorgi et al. 1988; Bottini/Fresa 1991), the Iron Age graves of San Teodoro-L'Incoronata (Chiartano 1977, 1994, 1996), the cemeteries of Sala Consilina of the $9^{\text {th }}$ to $5^{\text {th }}$ century BC (Kilian 1964 and 1970; La Genière 1968), the necropolis of a rural site in the territory of the Greek polis of Metapontion (Pizzica Pantanello; Carter 1998) and the necropolis of Taras (e.g. Lippolis 1994; Graepler 1997; Hempel 2001)

14 The most complete publications of sanctuaries are D’Andria 1978 (south-Apulian Santa Maria di Leuca) and Osanna / Sica 2005 (Torre di Satriano); but see also Olbrich 1979 (S. Biagio alla Venella), Fabricotti 1979 (Ruoti, Fontana Buona,), D’Andria 1990 and Ciaraldi 1999 (Oria-Monte Papalucio) and Adamesteanu / Dilthey 1992 (Rossano di Vaglio), Otto 1996 (Herakleia).

15 For summaries regarding the poleis of Taras and Metapontion, see De Juliis 2000 and 2001; for SirisHerakleia, see Neutsch 1967; Hänsel 1973; Pianu 1990; Giardino 1996.

16 For the rural site of Pizzica Pantanello in the territory of Metapontion, see, for instance, Carter 1998, 2001, 2011.

17 The most important reports concerning settlements in Basilicata-Lucania are those on Roccagloriosa (Gualtieri / Fracchia 1990 and 2001), Oppido Lucano (Lissi Caronna 1975. 1980, 1983), Torre di Satriano (Osanna 2009), Pomarico Vecchio (Barra Bagnasco 1997), Cozzo Presepe (Taylor et al. 1977) and Cività di Tricarico (de Cazanove 2008). For present-day Apulia there are substantial reports concerning Ordona (e.g. Mertens 1995) and Canosa (Cassano et al. 1992) in north-Apulia, Monte Sannace (Scarfì 1961 and 1962; Ciancio et al. 1989) and Gravina di Puglia (Small 1992) in central Apulia, and for Valesio (Boersma et 
Bio-archaeology is still in its infancy in southeast Italy. In many cases macro-remains of plants have not been systematically collected. Moreover, pollen do not preserve well in many districts of the region under discussion. There is still much to learn about the various crops and the vegetation of natural environments. The quantity of data concerning hunting and stock raising (animal bones) is steadily increasing, but the data are not so numerous that they allow us to have a good grip on farming and hunting in pre-Roman southeast Italy. There is some information on the human bones from burials. However, the present evidence is hopelessly insufficient to study health problems and life expectancy in the first millennium BC.

All in all, the enormous amount of data on southeast Italy generated in the past 30 years deserves it to be put in front of a wider public in a synthetic study. Although the quantity and character of the archaeological evidence varies from district to district, there is quite enough to create new images in which both regional changes and sub-regional variability are highlighted.

al. 1995; Yntema 2001), Cavallino di Lecce (Pancrazzi 1979, D'Andria 2005) and Vaste (D'Andria et al. 1990) in south-Apulia; for northern Calabria, reports have been published concerning Francavilla Maritti- ma (see http://www.museumfrancavilla/publications/) and Sybaris (various supplements to Notizie degli Scavi: Sibari I-V). 


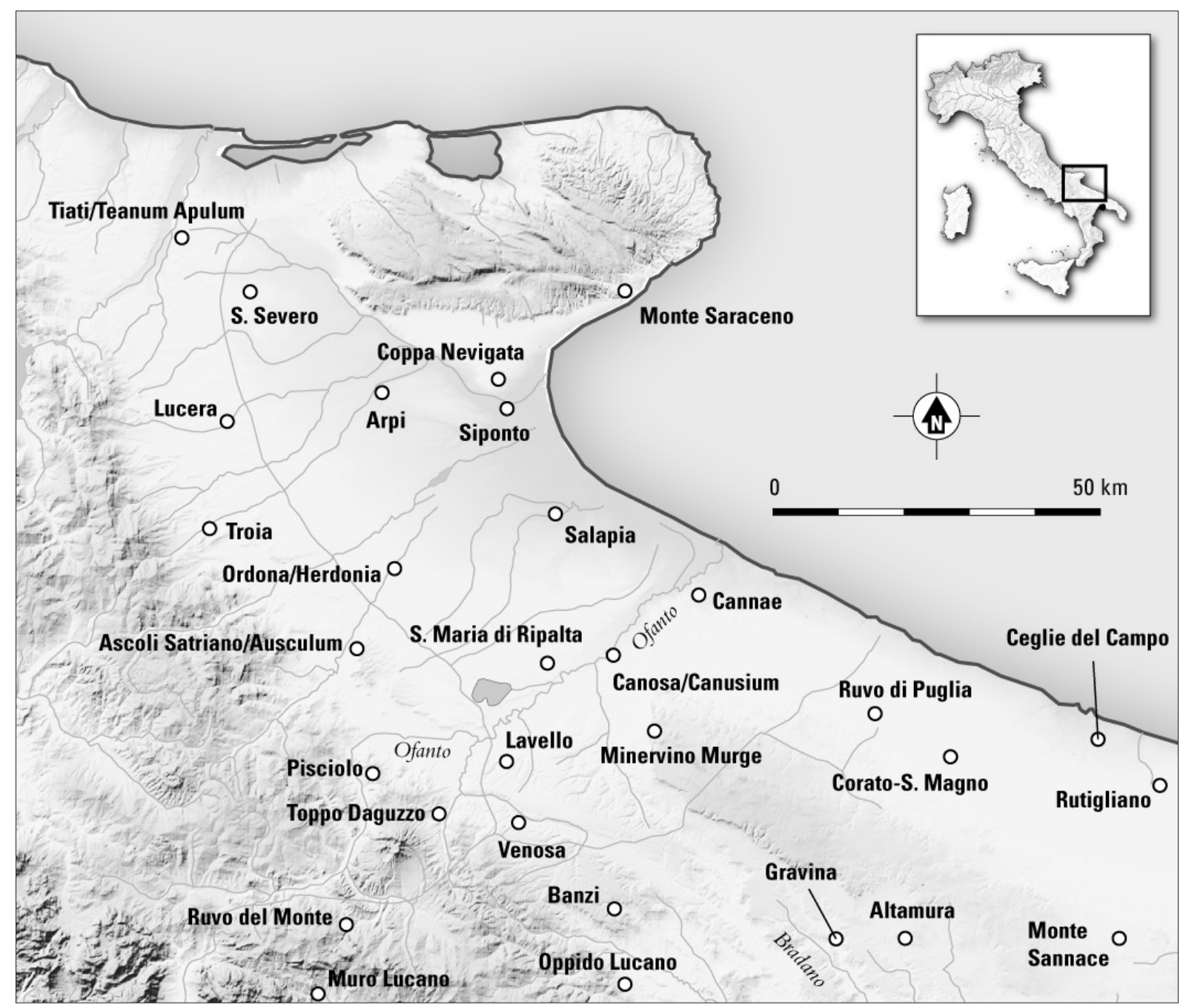

Fig. 1.1. North- and Central-Apulia: sites mentioned in the text. 


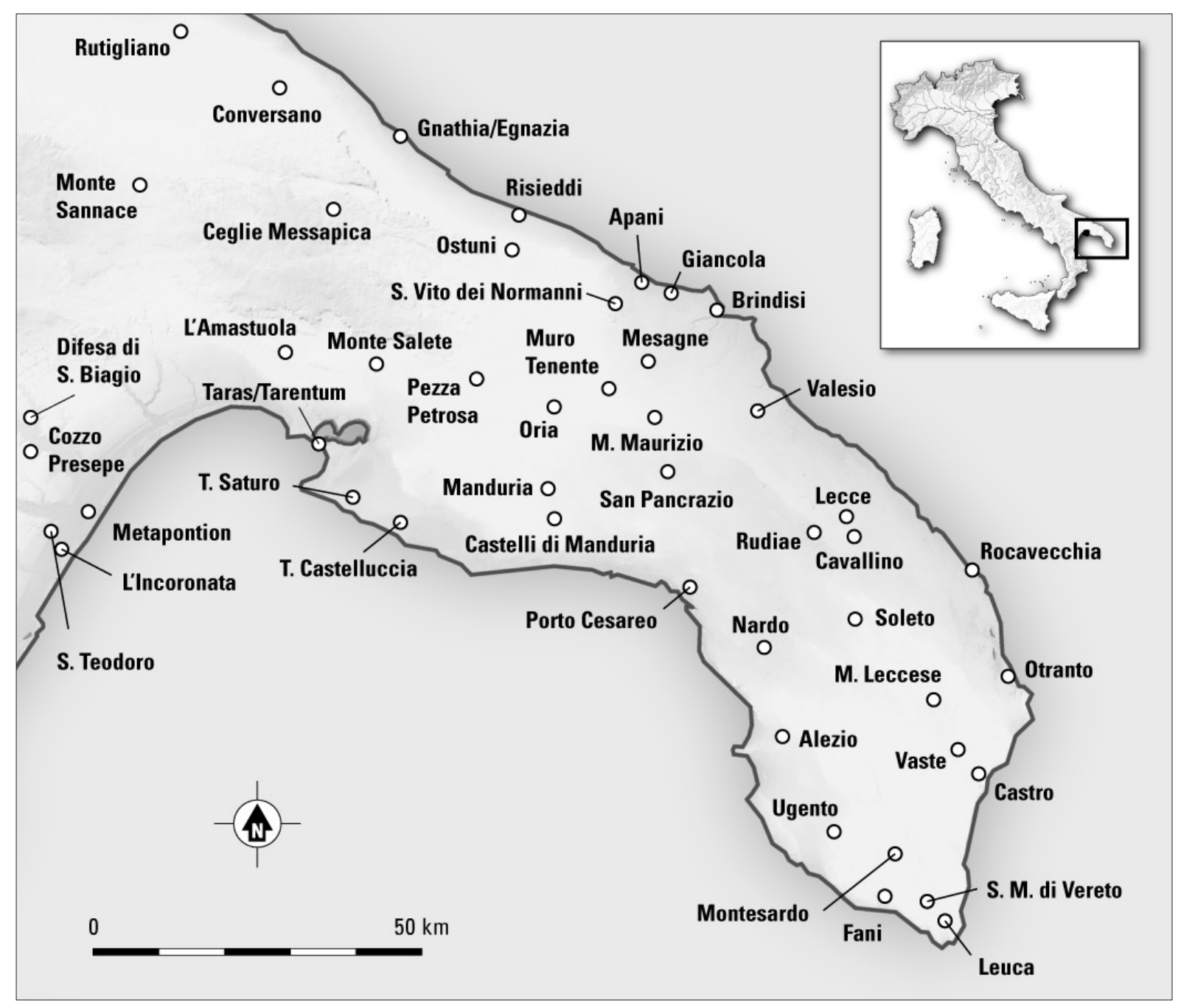

Fig. 1.2. South-Apulia: sites mentioned in the text. 


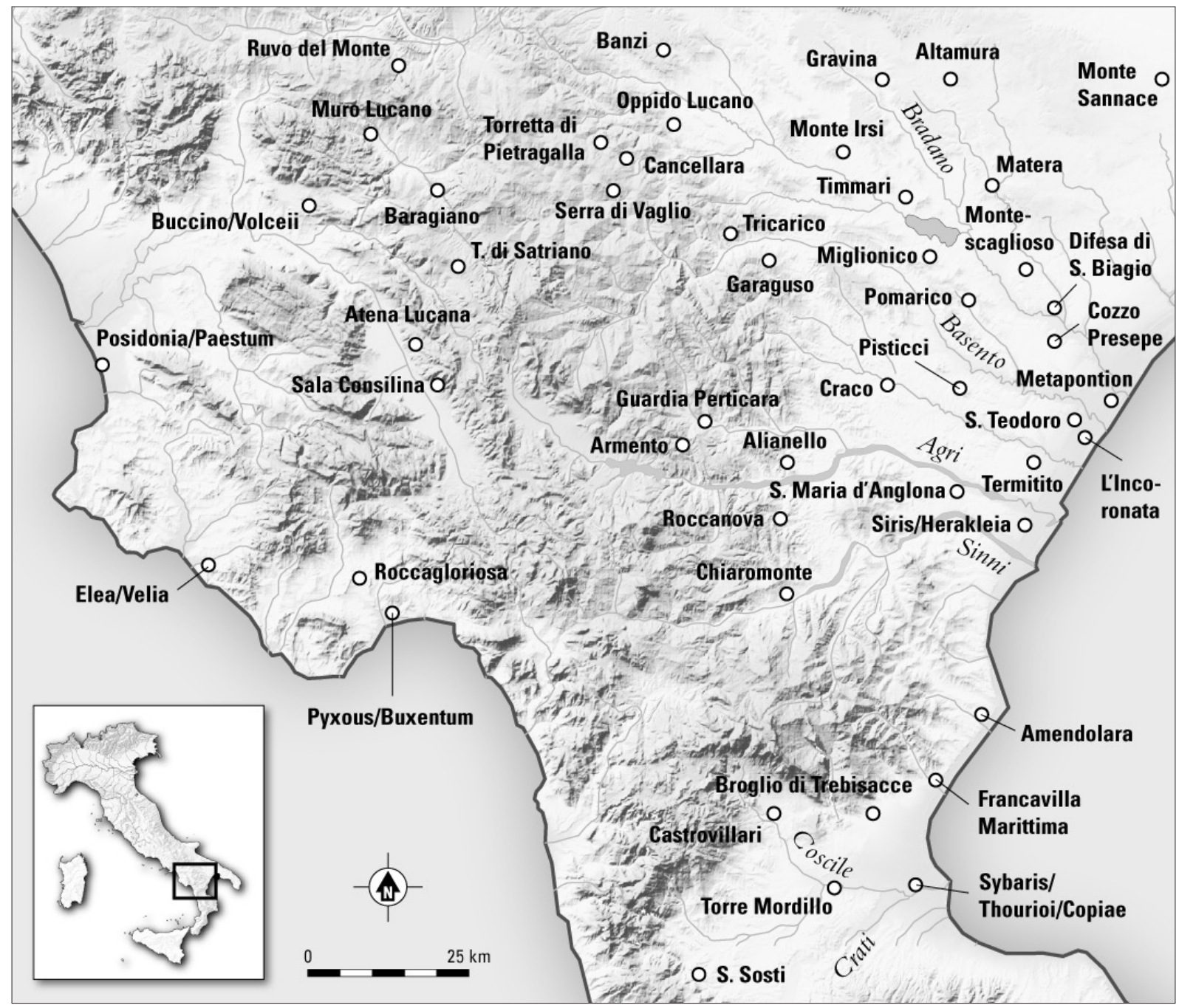

Fig. 1.3. Basilicata and north-Calabria: sites mentioned in the text. 